\title{
Pengaruh Kualitas Pelayanan dan Harga terhadap Penjualan (Studi pada Tongkleng Nglotok Yogyakarta)
}

\author{
Agus Dwi Cahya \\ Universitas Sarjanawiyata Tamansiswa ( UST), Yogyakarta, Indonesia \\ agusdc@ustjogja.ac.id
}

\section{Aramintha Jacinda Puteri}

Universitas Sarjanawiyata Tamansiswa ( UST), Yogyakarta, Indonesia araminthajacinda@gmail.com

\section{Malinda Sarah Sukma}

Universitas Sarjanawiyata Tamansiswa ( UST), Yogyakarta, Indonesia malindasarah7@gmail.com

\begin{abstract}
Abstrak Faktor penentu penjualan diantaranya adalah kualitas pelayanan dan harga. Dalam permasalahan penelitian ini adalah apakah kualitas pelayanan dan harga berpengaruh terhadap penjualan di Tongkleng Nglotok Yogyakarta secara simultan. Penelitian ini bertujuan bertujuan untuk menguji pengaruh kualitas pelayanan dan harga terhadap penjualan di Tongkleng Nglotok Yogyakarta. Tongkleng Ngelotok Yogyakarta ini merupakan salah satu kuliner yang diminati banyak masyarakat di Yogyakarta. Jenis penelitian ini adalah penelitian deskriptif dengan pendekatan kuantitatif. Subjek penelitian yaitu konsumen yang telah membeli produk di Tongkleng Nglotok Yogyakarta. Data Primer diperoleh dari angket dengan 50 responden dengan purposive sampling. Kemudian metode data yang dianalisis tersebut, dianalisis mengunakan analisis regresi linear berganda menggunakan SPSS release 25. Hasil penelitian ini diperoleh persamaan regresi linear berganda $\mathrm{Y}=$ 2,312+0,327 $\mathrm{X}_{1}-0,402 \mathrm{X}_{2}$. Koefisien determinasi simultan $\left(\mathrm{R}^{2}\right)$ disimpulkan dari kualitas pelayanan $\left(\mathrm{X}_{1}\right)$ dan harga $\left(\mathrm{X}_{2}\right)$ secara simultan sebesar 0,612 atau $61,2 \%$ berpengaruh terhadap penjualan di Tongkleng Ngelotok Yogyakarta. Hasil penelitan pada uji t menunjukkan bahwa variabel kualitas pelayanan $\left(\mathrm{X}_{1}\right)$ berpengaruh positif dan signifikan terhadap Penjualan (Y) dengan nilai sebesar 0,010 dan Variabel Harga $\left(\mathrm{X}_{2}\right)$ berpengaruh positif dan signifikan terhadap Penjual (Y) dengan nilai sebesar 0,007. Pada hasil Uji F Kualitas pelayanan dan harga secara simultan berpengaruh terhadap penjualan yang ditunjukan nilai signikansi 0,001
\end{abstract}

Kata Kunci Kualitas Pelayanan, Harga, Penjualan

\section{PENDAHULUAN}

Era globalisasi menyebabkan banyaknya perubahan dan perkembangan dalam Ilmu Pengetahuan dan Teknologi menjadi lebih modern sehingga menyebabkan pola hidup masyarakat Indonesia menjadi lebih praktis dan tidak lagi memasak makanan yang mereka 
makan sebanyak dahulu. Fenomena ini menimbulkan munculnya banyak persaingan dalam dunia bisnis yang memaksa para pelaku usaha (usahawan) untuk mengikuti alur bisnis yang semakin berkembang sesuai dengan kemajuan teknologi.

Seorang pelaku usaha dituntut untuk mengembangkan perencanaan bisnis strategi pemasaran volume penjualan, sehingga dapat membangun loyalitas dengan pelanggan dan membuat branding produk akan menjadi lebih diketahui. Untuk itu para pelaku usaha dituntut untuk melakukan inovasi terhadap pengembangan produk maupun jasa, karena sebuah inovasi dianggap sebagai kunci mutlak untuk kelangsungan suatu usaha bisnis. Inovasi dengan desai yang menarik tidak hanya dilihat untuk menaikkan laba dan keuntungan semata, namun meningkat kualitas produk dan jangkauan produk tersebut agar menjadi lebih luas.

Dewasa ini tak sedikit pelaku usaha yang terjun dalam bidang makanan dan minuman. Karena menyangkut kebutuhan dasar manusia, usaha dalam bidang ini merupakan bisnis abadi, Bisnis kuliner menjadi marak di temui diberbagai daerah, bahkan hingga ke wilayah pelosok. Karena bisnis kuliner merupakan bisnis yang dinilai mudah untuk berkembang dan banyak menghasilkan profit, sebagai contoh bisnis yang sedang berkembang adalah Restaurant.

Kualitas Pelayanan dan Harga mempunyai peranan yang sangat penting dalam mempengaruhi konsumen untuk membeli atau menggunakan produk atau jasa yang ditawarkan, karena Kualitas Pelayanan dan harga merupakan indikator pembelian yang digunakan oleh konsumen. Menurut (Armstrong Gary, Philip, 2012) harga adalah jumlah semua nilai yang diberikan oleh pelanggan untuk mendapatkan keuntungan dari memiliki atau menggunakan suatu produk atau jasa. Agar perusahaan dapat menguasai pasar yang lebih luas perusahaan perlu menetapkan harga yang bersaing dengan kualitas produk yang jauh lebih baik dari produk yang di tawarkan perusahaan pesaing guna mempengaruhi keputusan pembelian konsumen. Harga merupakan nilai suatu barang yang dijual kepada pembeli yang diukur dengan sejumlah uang tertentu sehingga terjadilah suatu transaksi jual beli antara pihak penjual dan pihak pembeli. (Vronin, J.J dan Taylor, 1992) mencatat bahwa faktor yang paling penting dalam kualitas layanan adalah pendapat dari pelanggan. Penjualan menurut (Buchari dan Alma, 2009) yaitu interaksi antara individu, saling bertemu muka yang ditujukan untuk menciptakan, memperbaiki, menguasai atau mempertahankan dengan pihak lain. Dengan tingkat harga bersaing yang merupakan salah satu faktor yang mempengaruhi meningkatnya volume penjualan pada suatu perusahaan.

\section{STUDI PUSTAKA}

\section{A. Manajemen Pemasaran}

Menurut (Kotler dan Armstrong, 2018) menjelaskan manajemen pemasaran ialah suatu upaya manusia untuk mencapai hasil pertukaran yang diinginkan dan membangun hubungan yang erat dengan konsumen dengan cara yang menguntungkan bagi perusahaan. Sedangkan (Stanton, Wiliam. J,. Etzel, Michael. J., Walker, 2001) mengatakan sarana yang didayagunakan oleh bisnis untuk menjalankan pemasaran.

\section{B. Kualitas Pelayanan}

Ada lima faktor yang mempengaruhi kualitas layanan yang diharapkan: janji perusahaan, tradisi dan pemikiran, pengalaman sebelumnya, tradisi lisan dan komunikasi, dan keinginan pribadi. Adapun faktor-faktor yang mempengaruhi layanan yang diakui, ada tiga faktor: fisik perusahaan dan sumber daya teknis, pekerja dari layanan pelanggan, dank lien yang berpartisipasi. Enam faktor komposisi kualitas telah disajikan oleh (Gronross, 1984), yaitu: Profesionalisme dan teknologi, Sikap dan Perilaku, Aksesibilitas dan fleksibilitas, Keandalan dan kepercayaan, Pemulihan layanan, Reputasi dan Kredibilitas. 


\section{Harga}

Menurut (Kotler dan Armstrong, 2018) Dalam arti yang sempit harga (price) adalah jumlah yang ditagihkan atas suatu produk atau jasa, lebih luas lagi harga dalah jumlah semua nilai yang diberikan oleh pelanggan untuk mendapatkan keuntungan dari memiliki atau menggunakan suatu produk atau jasa. Menurut (Tjiptono, 2015) Harga menjadi faktor utama yang dapat mempengaruhi pilihan seorang pembeli, harga cukup berperan dalam menentukan pembelian konsumen, untuk itu sebelum menetapkan suatu harga, sebaiknya perusahaan melihat beberapa refrensi harga suatu produk yang dinilai cukup tinggi dalam penjualan. Menurut (Philip and Armstrong, 2008) ada 4 indikator yang mencirikan harga, yaitu: keterjangkauan harga, kesesuaian harga dengan kualitas produk, daya saing harga, dan kesesuaian harga dengan manfaat.

\section{Penjualan}

Menurut (Abdullah Thamrin dan Francis Tantri, 2016) Penjualan adalah bagian dari promosi dan promosi adalah salah satu bagian dari keseluruhan sistem pemasaran. Menurut (Basu Swastha dan Irawan, 2014) penjualan adalah suatu proses pertukaran barang atau jasa antara penjual dan pembeli. Menurut (Kotler, 1993) menyatakan adapun indikator indikator penjualan sebagai berikut : harga, promosi, kualitas, saluran.

\section{1) KERANGKA PEMIKIRAN}

Untuk menunjukkan suatu arah dari penyusunan agar dapat memperoleh gambaran yang lebih jelas, maka dalam penelitian ini penulis membuat suatu kerangka pemikiran. Kerangka pemikiran dalam penelitian ini adalah sebagai berikut:

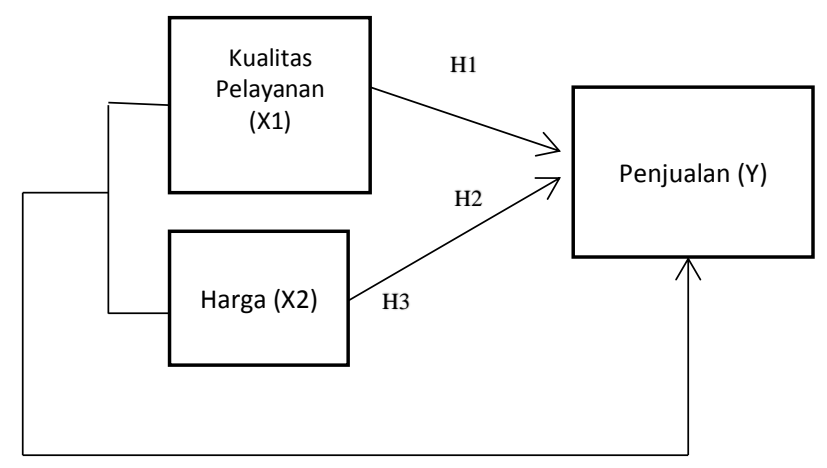

\section{Gambar 1. Kerangka penelitian}

Berdasarkan kajian teori dan kerangka penelitian, maka dapat dirumuskan hipotesis sebagai berikut:

H1: Kualitas pelayanan berpengaruh positif dan signifikan terhadap penjualan

$\mathrm{H} 2$ : Harga berpengaruh positif dan signifikan terhadap penjualan

H3: Kualitas pelayanan dan harga berpengaruh positif terhadap penjualan

\section{METODE PENELITIAN}

\section{A. Variabel Penelitian}


Dalam penelitian ini variabel yang digunakan terdiri dari variabel dependen dan variabel independen. Variabel dependen yang digunakan yaitu penjualan, dan variabel independen yang digunakan yaitu kualitas pelayanan dan harga.

\section{B. Populasi dan Sampel}

Populasi dalam penelitian ini adalah konsumen Tongkleng Nglotok Yogyakarta. Metode sampling pada penelitian ini menggunakan metode purposive sampling, yaitu dengan menentukan responden sesuai dengan kriteria yang dibutuhkan, yakni pelanggan yang pernah berkunjung dan order di Tongkleng Nglotok Yogyakarta, baik yang berjenis kelamin laki-laki maupun perempuan dan pendidikan terakhir.

\section{Metode Analisis Data}

Dalam penelitian ini, analisis yang digunakan adalah analisis deskriptif dengan pendekatan kuantitatif. Penelitian ini menggunakan data yang bersumber dari data primer, yaitu data yang diperoleh secara langsung dari responden melalui kuesioner. Metode pengumpulan data yang dilakukan dengan cara menyebar angket atau kuesioner. Teknik pengumpulan data menggunakan skala Likert lima poin yaitu: Sangat Setuju $(\mathrm{SS}=5)$; Setuju $(\mathrm{S}=4)$; Netral $(\mathrm{N}=$ 3); Tidak Setuju (TS = 2) dan Sangat Tidak Setuju (STS = 1).

Teknik analisis data menggunakan:

\section{Uji Asumsi Klasik}

a. Uji Normalitas, Menurut (Ghozali Imam, 2013) uji normalitas bertujuan untuk menguji apakah dalam model regresi, variabel regresi pengganggu atau residual memiliki distribusi yang normal. Selain itu uji statistik lain yang dapat digunakan untuk menguji normalitas residual data penelitian adalah uji statistik non-parametrik Kolmogorov Smirnov (K-S).

b. Uji multikolinearitas, Untuk menguji korelasi antar variabel independent, bila terjadi korelasi berarti ada problem multikolinieritas. Untuk menguji melihat tolerance variabel independent dan Variance Inflation Factor (VIF).

c. Uji heteroskedastisitas, Menurut Ghozali (2009) mendefinisikan bahwa uji heteroskesdatisitas bertujauan untuk mnguji apakah model regresi terjadi ketidaksamaan variance dari residual satu pengamatan ke pengamatan lain.

d. Uji autokorelasi, merupakan pengujian dimana variabel dependen tidak berkorelasi dengan nilai variabel itu sendiri, baik nilai periode sebelumnya maupun nilai periode setelahnya. Dilakukan dengan run test, run test bertujuan untuk melihat apakah data residual terjadi secara random atau tidak.

\section{Analisis Regresi Linear Berganda}

Analisis regresi linear berganda merupakan analisis peramalan nilai pengaruh dua variabel terikat untuk membuktikan ada atau tidaknya hubungan fungsi atau kausal antara dua variabel bebas dengan satu variabel terikat. Persamaan regresi berganda sebagai berikut:

$$
\begin{aligned}
& \mathbf{Y = a}+\mathbf{b}_{1} \mathbf{X}_{\mathbf{1}}+\mathbf{b}_{\mathbf{2}} \mathbf{X}_{\mathbf{2}}+\mathbf{e} \\
& \mathrm{Y}=\frac{1}{\text { Penjualan }} \\
& \mathrm{A}=\text { Konstanta dari Persamaan Regresi } \\
& \mathrm{b}_{1}=\text { Koefisien regresi dari Kualitas Pelayanan } \\
& \mathrm{X}_{1}=\text { Variabel Kualitas Pelayanan } \\
& \mathbf{b}_{2}=\text { Koefisien regresi dari Harga }
\end{aligned}
$$


$\mathrm{X}_{2}=$ Variabel Harga

a. Uji t, digunakan untuk mengetahui pengaruh $\mathrm{X}$ terhadap $\mathrm{Y}$ secara parsial atau individu. Mengetahui variabel independen terhadap variabel dependen secara parsial dapat dibandingkan antara nilai probabilitas signifikannya dengan derajar kepercayaan 5\% $(0,05)$.

b. Uji F, digunakan untuk menguji pengaruh dari variabel independen terhadap dependen secara bersamaan.

\section{HASIL DAN PEMBAHASAN}

\section{Karakteristik Responden}

Pada penelitian ini proses penyebaran kuesioner ditujukan kepada konsumen/ pelanggan di Tongkleng Nglotok Yogyakarta dengan kriteria yang telah di tetapkan.Kuesioner disebar melalui media google forms. Data yang terkumpul sebanyak 50 data responden yang dapat memberikan informasi yang dibutuhkan untuk penelitian ini

Tabel 1

\section{Kriteria Responden}

Sumber: Hasil Angket

\begin{tabular}{|c|l|c|c|}
\hline \multicolumn{2}{|c|}{ Karakteristik Responden } & Jumlah & Prosentase \\
\hline \multirow{2}{*}{$\begin{array}{c}\text { Jenis } \\
\text { Kelamin }\end{array}$} & Laki-Laki & 20 & $40 \%$ \\
\cline { 2 - 4 } & Perempuan & 30 & $60 \%$ \\
\hline \multirow{4}{*}{ Pekerjaan } & Mahasiswa & 39 & $78 \%$ \\
\cline { 2 - 4 } & Karyawan & 8 & $14 \%$ \\
\cline { 2 - 4 } & Lainya & 3 & $6 \%$ \\
\hline
\end{tabular}

Disimpulkan bahwa responden terbanyak yaitu perempuan dengan presentase $60 \%$, Dengan pekerjaan yaitu mahasiswa sebanyak $78 \%$

\section{Uji Validitas dan Uji Reliabilitas}

Pada uji validitas ini penelitian melalui angket yang diberikan kepada responden, responden yang digunakan yaitu berjumlah 50 responden. Berikut hasil uji validitas penelitian

Tabel 2. Hasil Uji Validitas

\begin{tabular}{|l|c|c|c|l|}
\hline \multicolumn{5}{|c|}{ Kualitas Pelayanan } \\
\hline Item & Pearson Corelation & R Tabel & Sig Hitung & Keterangan \\
\hline X1.1 & 0,864 & 0,279 & 0,00 & Valid \\
\hline X1.2 & 0,690 & 0,279 & 0,00 & Valid \\
\hline X1.3 & 0,882 & 0,279 & 0,00 & Valid \\
\hline X1.4 & 0,716 & 0,279 & 0,00 & Valid \\
\hline X1.5 & 0,782 & 0,279 & 0,00 & Valid \\
\hline
\end{tabular}




\begin{tabular}{|l|c|c|c|l|}
\hline \multicolumn{5}{|c|}{ Harga } \\
\hline Item & Pearson Corelation & R Tabel & Sig Hitung & Keterangan \\
\hline X2.1 & 0,895 & 0,279 & 0,00 & Valid \\
\hline X2.2 & 0,873 & 0,279 & 0,00 & Valid \\
\hline X2.3 & 0,885 & 0,279 & 0,00 & Valid \\
\hline X2.4 & 0,822 & 0,279 & 0,00 & Valid \\
\hline
\end{tabular}

Sumber: Data diolah penulis (2021)

\begin{tabular}{|c|c|c|c|c|}
\hline \multicolumn{5}{|c|}{ Penjualan } \\
\hline Item & Pearson Corelation & R Tabel & Sig Hitung & Keterangan \\
\hline Y.1 & 0,789 & 0,279 & 0,00 & Valid \\
\hline Y.2 & 0,742 & 0,279 & 0,00 & Valid \\
\hline Y.3 & 0,840 & 0,279 & 0,00 & Valid \\
\hline Y.4 & 0,787 & 0,279 & 0,00 & Valid \\
\hline
\end{tabular}

Sumber: Data diolah penulis (2021)

Berdasarkan tabel 2, dapat dilihat bahwasanya hasil uji validitas pada variabel kualitas pelayanan, harga dan penjualan dikatakan valid karena setiap pertanyaan memiliki nilai pearson correlation $>0.279$.

Dibawah ini hasil uji reliabilitas dari penelitian sebagai berikut :

Tabel 3

Hasil Uji Reliabilitas

\begin{tabular}{|l|c|c|l|}
\hline \multicolumn{1}{|c|}{ Item } & Nilai Crobach's Alpha & Nilai Kritis & Keterangan \\
\hline Kualitas Pelayanan (X1) & 0,849 & 0,60 & Reliabel \\
\hline Harga (X2) & 0,887 & 0,60 & Reliabel \\
\hline Penjualan (Y) & 0,799 & 0,60 & Reliabel \\
\hline
\end{tabular}

Sumber: Data diolah penulis (2021)

Berdasarkan tabel 3 data yang sudah diolah didapatkan hasil nilai Cronchbach Alpha pada variabel kualitas pelayanan dengan nilai 0,849 dan variabel harga dengan nilai 0,887 serta variabel penjualan dengan nilai 0,779 . Suatu model dikatakan reliabel apabila memiliki nilai cronbach alpha $>0,60$. Maka dapat disimpulkan bahwasanya, semua item instrumen atau angket yang digunakan reliabel dan layak digunakan untuk mengumpulkan data.

\section{1) HASIL ANALISA DATA}

\section{A. Uji Asumsi Klasik}




\section{Uji Normalitas Data}

Dimaksudkan untuk menguji apakah nilai residual telah distandarisasi pada modal regresi berdistribusi normal atau tidak. Nilai residual dikatakan berdistribusi normal jika nilai residual terstandasrisasi tersebut sebagai besar mendekati nilai rata-rata (Suliyanto, 2011). Uji normalitas pada penelitian ini menggunakan uji statistik non-parametrik Kolomogrov-Smirnov. Nilai residual terstandarisasi berdistribusi normal jika nilai sig. > alpha

\section{Tabel 4 \\ Uji Normalitas Data}

\begin{tabular}{|c|c|c|}
\hline \multicolumn{3}{|c|}{ One-Sample Kolmogorov-Smirnov Test } \\
\hline & & Unstandardized Residual \\
\hline \multicolumn{2}{|l|}{$\mathrm{N}$} & 50 \\
\hline \multirow{2}{*}{ Normal Parametersa,b } & Mean & 0,0000000 \\
\hline & Std. Deviation & 1,48381681 \\
\hline \multirow{3}{*}{ Most Extreme Differences } & Absolute & 0,081 \\
\hline & Positive & 0,079 \\
\hline & Negative & $-0,081$ \\
\hline \multicolumn{2}{|l|}{ Test Statistic } & 0,081 \\
\hline \multicolumn{2}{|c|}{ Asymp. Sig. (2-tailed) } & 200 \\
\hline
\end{tabular}

Sumber: Hasil IBM SPSS versi 25 yang diolah penulis 2021

Berdasarkan tabel 4 dapat dilihat bahwa nilai Asymp. Signifikansi sebesar 0,200 > 0,05, sehingga dapat disimpulkan bahwa data residual mengikuti distribusi normal.

Selain dengan menggunakan metode Kolomogrov-Smirnov dapat juga dilihat dari analisis grafik histogram yang digunakan untuk melihat normalitas residual yang telah membandingkan antara data observasi dengan melihat probability plot yang telah membandingkan distribusi kumulatif dari distribusi normal. Adapun penjelasannya sebagai berikut : 


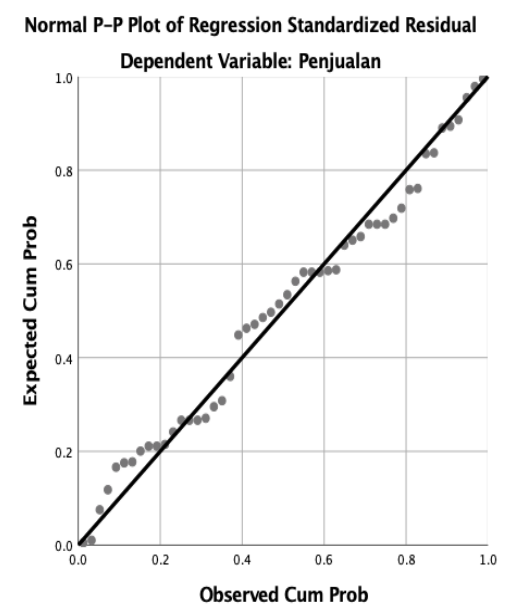

Gambar 2

Grafik Scatterplot

Dari gambar 2 terlihat bahwa data menyebar di sekitar garis diagonal dan mengikuti arah garis diagonal hal tersebut dapat dikatakan bahwa data penelitian sudah memenuhui uji normalitas, sehinggga sudah layak untuk diolah dengan analisis regresi. Dibawah ini uji normalitas dengan histogram:

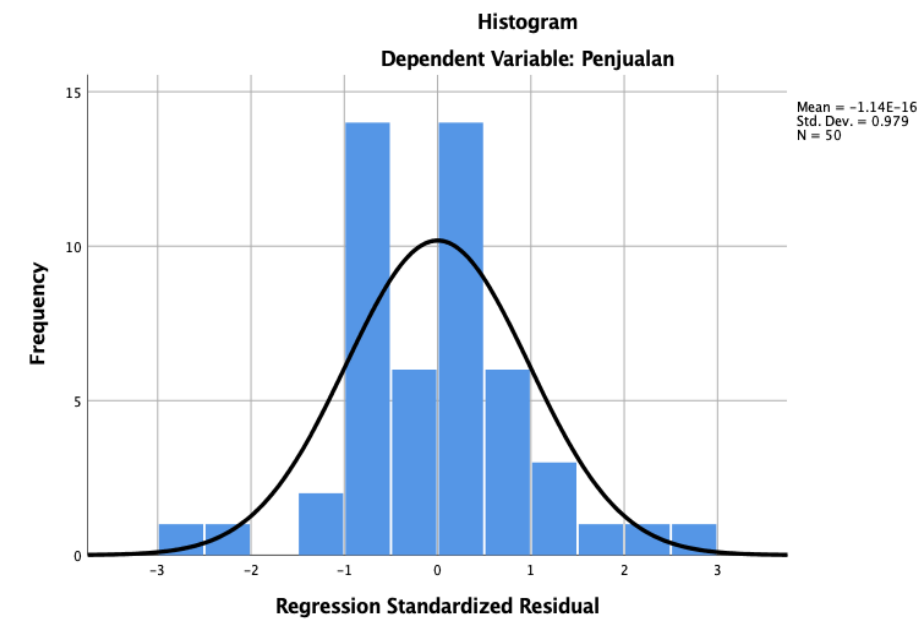

Gambar 3

Grafik Histogram

Berdasarkan gambar diatas bahwa tampilan histogram menunjukkan pola yang membentuk lonceng dan memiliki nilai Std. sebesar 0,979>0,80 dapat disimpulkan bahwa distribusi data tersebut normal.

\section{Uji Multikolinieritas}

Tabel 5

Hasil Uji Multikolinieritas Coefficients

\begin{tabular}{|c|c|c|c|c|c|c|c|}
\hline \multirow{2}{*}{ Model } & \multicolumn{2}{|c|}{ Unstandardized Coefficients } & $\begin{array}{c}\text { Standardized } \\
\text { Coefficients }\end{array}$ & \multirow{2}{*}{$\mathrm{T}$} & \multirow{2}{*}{ Sig. } & \multicolumn{2}{|c|}{$\begin{array}{c}\text { Collinearity } \\
\text { Statistics }\end{array}$} \\
\cline { 2 - 4 } & $\mathrm{B}$ & Std. Error & Beta & & & Tolerance & VIF \\
\hline
\end{tabular}




\begin{tabular}{|l|l|r|r|r|r|r|r|l|}
\hline 1 & (Constant) & 2,312 & 1,502 & & 1,539 & 0,131 & & \\
\cline { 2 - 9 } & $\begin{array}{l}\text { Kualitas } \\
\text { Pelayanan }\end{array}$ & 0,327 & 0,122 & 0,401 & 2,673 & 0,010 & 0,366 & 2,732 \\
\cline { 2 - 9 } & Harga & 0,402 & 0,142 & 0,424 & 2,823 & 0,007 & 0,366 & 2,732 \\
\hline
\end{tabular}

Sumber: Output SPSS versi 25, diolah oleh penulis 2021

Berdasarkan tabel 5 dapat diketahui bahwa seluruh variabel independen yaitu kualitas pelayanan (X1) dan Harga (X2) digunakan dalam penelitian mempunyai nilai toleran $>0,10$ yaitu sebesar 0,366>0,10 dan nilai VIF $<10,00$ yaitu sebesar 2,732 < 10,00. Maka data tersebut tidak terjadi multikolinearitas.

Dapat disimpulkan bahwa tidak ditemukan multikolonieritas sehingga variabel independen tersebut dapat digunakan untuk penelitian.

\section{Uji Heterokesdastisitas}

Hasil autokorelasi pada tabel 6 menunjukkan bahwa nilai test yang didapat adalah -0.857 dengan probabilitas 0,391 yang berarti tidak signifikansi pada 0,05. Sehingga hipotesis nol diterima, dan disimpulkan bahwa residual adalah random atau tidak terjadi autokorelasi antar nilai residual.

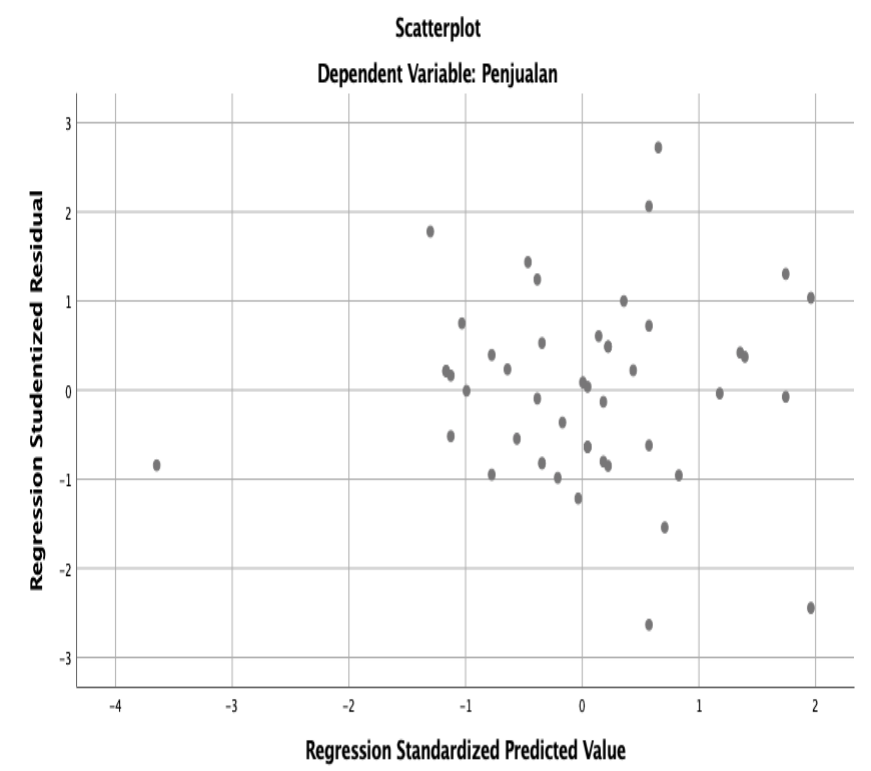

Gambar 4

Grafik Scatterplot

\section{Hasil Uji Autokolerasi}

\begin{tabular}{|l|l|}
\hline & $\begin{array}{l}\text { Unstandardized } \\
\text { Residual }\end{array}$ \\
\hline $\mathrm{Z}$ & $-0,857$ \\
\hline Asymp.Sig & 0,391 \\
\hline
\end{tabular}


Sumber: Output SPSS versi 25, diolah penulis 2021

B. Analisis Regregi Linear Berganda

1. Hasil Analisis Regresi Linier Berganda

Tabel 7

Hasil Uji analisis Regresi Linier Berganda Coefficients

\begin{tabular}{|c|l|c|c|c|c|c|}
\hline \multirow{2}{*}{ Model } & \multicolumn{2}{c|}{$\begin{array}{c}\text { Unstandardized } \\
\text { Coefficients }\end{array}$} & $\begin{array}{c}\text { Standardized } \\
\text { Coefficients }\end{array}$ & t & Sig. \\
\cline { 3 - 7 } & B & Std. Error & Beta & & \\
\hline \multirow{2}{*}{$\mathbf{1}$} & 2,312 & 1,502 & & 1,539 & 0,131 \\
\cline { 2 - 7 } & $\begin{array}{l}\text { Kualitas } \\
\text { Pelayanan }\end{array}$ & 0,327 & 0,122 & 0,401 & 2,673 & 0,010 \\
\cline { 2 - 8 } & Harga & 0,402 & 0,142 & 0,424 & 2,823 & 0,007 \\
\hline
\end{tabular}

Sumber: Output SPSS versi 25, diolah penulis 2021

Berdasarkan tabel 7 diatas, dapat diketahui persamaan regresi linear berganda sebagai berikut:

$$
Y=2,312+0,327 X_{1}-0,402 X_{2}
$$

Keterangan:

$$
\begin{aligned}
\mathrm{Y} & =\text { Penjualan } \\
\mathrm{a} & =2,312 \\
\mathrm{~b}_{1} & =0,327 \\
\mathrm{~b}_{2} & =-0,402 \\
\mathrm{X}_{1} & =\text { Kualitas Pelayanan } \\
\mathrm{X}_{2} & =\text { Harga }
\end{aligned}
$$

\section{Koefisien Determinasi $\left(\mathbf{R}^{2}\right)$}

Tabel 8. Hasil Analisis Koefisien Determinasi $\left(\mathbf{R}^{\mathbf{2}}\right)$

\begin{tabular}{|c|c|c|c|c|}
\hline Model & $\mathbf{R}$ & R Square & $\begin{array}{c}\text { Adjusted } \\
\text { R Square }\end{array}$ & $\begin{array}{c}\text { Std. Error of } \\
\text { the Estimate }\end{array}$ \\
\hline 1 & 0,782 & 0,612 & 0,595 & 1,51506 \\
\hline
\end{tabular}

Sumber: Output SPSS versi 25, diolah penulis 2021

Berdasarkan tabel 8 dapat diketahui bahwa koefisien determinasi nilai R Square sebesar 0,782. Dapat disimpulkan bahwa besarnya kontribusi variabel independen kualitas pelayanan $\left(\mathrm{X}_{1}\right)$ dan Harga $\left(\mathrm{X}_{2}\right)$, secara simultan berpengaruh terhadap penjualan Tongkleng Nglotok Yogyakarta 0,612 atau 61,2\%, dipengaruhi oleh variabel lain dari luar variabel yang diteliti.

\section{Uji Hipotesis}
a. Uji t

\section{Hasil Uji t (Persial)}




\begin{tabular}{|l|c|c|c|c|c|}
\hline \multirow{2}{*}{ Model } & \multicolumn{2}{|c|}{ Unstandardized Coefficients } & $\begin{array}{c}\text { Standardized } \\
\text { Coefficients }\end{array}$ & t & Sig. \\
\cline { 2 - 5 } & $\mathbf{B}$ & Std. Error & Beta & & \\
\hline (Constant) & $\mathbf{2 , 3 1 2}$ & $\mathbf{1 , 5 0 2}$ & & $\mathbf{1 , 5 3 9}$ & $\mathbf{0 , 1 3 1}$ \\
\hline Kualitas Pelayanan & $\mathbf{0 , 3 2 7}$ & $\mathbf{0 , 1 2 2}$ & $\mathbf{0 , 4 0 1}$ & $\mathbf{2 , 6 7 3}$ & $\mathbf{0 , 0 1 0}$ \\
\hline Harga & $\mathbf{0 , 4 0 2}$ & $\mathbf{0 , 1 4 2}$ & $\mathbf{0 , 4 2 4}$ & $\mathbf{2 , 8 2 3}$ & $\mathbf{0 , 0 0 7}$ \\
\hline
\end{tabular}

Sumber: Output SPSS versi 25, diolah penulis 2021.

Berdasarkan hasil uji t diketahui kualitas pelayanan dengan tingkat signifikansi 0,010 yang artinya lebih kecil dari 0,05 variabel kualitas pelayanan secara parsial memiliki pengaruh terhadap penjualan, sedangkan pada variabel harga memiliki nilai signifikansi 0,007 yang artinya lebih kecil dari 0,05 variabel harga secara parsial memiliki pengaruh terhadap penjual

b. Uji F

\begin{tabular}{|l|c|c|c|c|c|}
\hline \multicolumn{1}{|c|}{ Model } & Sum of Squares & df & Mean Square & F & Sig. \\
\hline Regression & 170,136 & 2 & 85,068 & 7,77 &, 001 \\
\hline Residual & 107,884 & 47 & 2,295 & & \\
\hline Total & 278,020 & 49 & & & \\
\hline
\end{tabular}

Berdasarkan output di atas diketahui nilai signifikansi untuk pengaruh X1 dan X2 secara simultan terhadap Y adalah sebesar $0,001<0,05$ sehingga dapat disimpulkan secara simultan terdapat pengaruh kualitas pelayanan (X1) dan harga (X2) terhadap penjualan (Y).

\section{2) PEMBAHASAN}

\section{A. Pengaruh kualitas pelayanan terhadap penjualan}

Berdasarkan nilai statistik dari uji t, yaitu kualitas pelayanan dengan tingkat signifikansi 0,010 yang artinya lebih kecil dari 0,05. Sehingga dapat dikatakan bahwa kualitas pelayanan berpengaruh signifikan terhadap penjualan. Hal ini berarti semakin meningkat kualitas pelayanan di Tongkleng Nglotok Yogyakarta maka akan meningkatkan penjualan di Tongkleng Nglotok Yogyakarta.

\section{B. Pengaruh harga terhadap penjualan}

Berdasarkan hasil dari uji t menunjukkan variabel harga memiliki nilai signifikansi 0,007 yang artinya lebih kecil dari 0,05. Maka bisa disimpulkan bahwa harga berpengaruh signifikan terhadap penjualan. Dari hasil tersebut dapat di simpulkan bahwa harga yang ditawarkan di Tongkleng Nglotok Yogyakarta seperti, harga terjangkau, harga sesuai dengan kualitas produk, diskon atau potongan harga mempengaruhi penjualan.

\section{Pengaruh kualitas produk dan harga terhadap keputusan pembelian}

Berdasarkan hasil analisis koefisien determinasi $\left(\mathrm{R}^{2}\right)$ bahwa besarnya kontribusi variabel independen kualitas produk $\left(\mathrm{X}_{1}\right)$ dan Harga $\left(\mathrm{X}_{2}\right)$, secara simultan berpengaruh 
terhadap keputusan pembelian produk di Tongkleng Nglotok Yoyakarta sebesar 0,612 atau $61,2 \%$, dipengaruhi oleh variabel lain dari luar variabel yang diteliti. Variabel yang memiliki kontribusi besar adalah kualitas pelayanan dan harga.

\section{KESIMPULAN}

Berdasarkan hasil pengujian dapat diambil beberapa kesimpulan, antara lain : Variabel kualitas pelayanan berpengaruh positif dan signifikan terhadap penjualan dengan nilai 0,010 , sehingga kualitas pelayanan berpengaruh terhadap penjualan di Tongkleng Nglotok Yogyakarta. Variabel harga berpengaruh positifdan signifikan terhadap penjualan dengan nilai signifikansi 0,007, sehingga harga berpengaruh terhadap penjualan di Tongkleng Nglotok Yogyakarta. Variabel kualitas pelayanan dan variabel harga pada uji $\mathrm{F}$ secara simultan/bersama-sama berpengaruh positif dan terhadap penjualan dengan dengan nilai 0,001

\section{DAFTAR PUSTAKA}

Abdullah Thamrin dan Francis Tantri. (2016). ManajemenPemasaran. PT. Raja Grafindo Persada.

Armstrong Gary, Philip, K. (2012). Prinsip-Prinsip Pemasaran: Vol. 13 Jilid 1. Erlangga

Basu Swastha dan Irawan. (2014). Manajemen Pemasaran Modern.

Buchari dan Alma. (2009). Manajemen Pemasaran dan Pemasaran Jasa (Kedelapan). Alfabeta.

Ghozali, I. (2009). Aplikasi Analisis Multivariate dengan Program SPSS. Edisi Keempat, Penerbit Universitas Diponegoro.

Ghozali Imam. (2013). Aplikasi Analisis Multivariate dengan Program IBM SPSS 21 Update PLS Regresi. Badan Penerbit Universitas Diponegoro.

Gronross, C. (1984). A service Quality Model and Its Marketing Implications. European Journal of Marketing, 18 No 4, 36-44.

Kotler. (1993). Manajemen Pemasaran (Analisis perencanaan, implementasi dan pengendalian). Lembaga Penerbit Fakultas Ekonomi UNiversitas Indonesia.

Kotler dan Armstrong. (2018). Principles of Marketing. 15 Global.

Philip and Armstrong. (2008). Prinsip-Prinsip Pemasaran. Erlangga.

Stanton, Wiliam. J,. Etzel, Michael. J., Walker, B. J. (2001). Fundamental of Marketing (8th Editon). International Mc.Craw-Hil.

Suliyanto. (2011). Ekonometrika Terapan: Teori Dan Aplikasi Dengan SPSS (Edisi 1). ANDI Yogyakarta.

Tjiptono, F. (2015). Strategi Pemasaran (4th ed.). ANDI

Vronin, J.J dan Taylor, S. A. (1992). Measuring Service Quality: A Reexaminataion and Extension. Journal of Marketing, Juny (56), 55-68.

Yuniati, Y. (2016). Pengaruh Kualitas Produk, Harga, dan Kepercayaan terhadap Keputusan Pembelian Produk Fashion Online. In Issn:0852-8349 (Vol. 18, Issue 1, pp. 27-37 